Article

\title{
Aging Characteristics of Asphalt Binder under Strong Ultraviolet Irradiation in Northwest China
}

\author{
Ling Zou ${ }^{1,2,3, *}$, Yan Zhang ${ }^{2}$ and Bangyi Liu ${ }^{1}$ \\ 1 School of Transportation, Southeast University, Nanjing 211189, China; 230169539@seu.edu.cn \\ 2 CCCC First Highway Consultants Co., Ltd., Xi'an 710075, China; zhangyan@ccroad.com.cn \\ 3 School of Highway, Chang'an University, Xi'an 710064, China \\ * Correspondence: lingzou@seu.edu.cn
}

check for

updates

Citation: Zou, L.; Zhang, Y.; Liu, B. Aging Characteristics of Asphalt Binder under Strong Ultraviolet Irradiation in Northwest China. Sustainability 2021, 13, 10753. https://doi.org/10.3390/ su131910753

Academic Editors: Pooyan Ayar, Augusto Cannone Falchetto, Hamed Majidifard and Xiaolong Zou

Received: 28 July 2021

Accepted: 18 September 2021

Published: 28 September 2021

Publisher's Note: MDPI stays neutral with regard to jurisdictional claims in published maps and institutional affiliations.

Copyright: (c) 2021 by the authors. Licensee MDPI, Basel, Switzerland. This article is an open access article distributed under the terms and conditions of the Creative Commons Attribution (CC BY) license (https:/ / creativecommons.org/licenses/by/ $4.0 /)$.

\begin{abstract}
Asphalt pavement is significantly affected by ultraviolet (UV) aging. Therefore, the establishment of an asphalt UV aging evaluation system is desirable for highway construction in areas which experience strong UV radiation. In this study, Dunhuang City in Gansu Province (northwest China) was used as the research site. Base and SBS modified asphalts were selected, and their performance changes before and after UV aging were studied. An asphalt UV aging evaluation system was established, including the conditions for an indoor, accelerated UV aging test as well as evaluation indicators. The results showed that the adverse effect of UV aging on asphalt performance was greater than that of RTFOT and PAV, and that the low-temperature performance of asphalt degraded most rapidly. SBS modified asphalt was more resistant to UV aging than base asphalt, while 60/80 pen grade base asphalt was found to be unsuitable for use on pavements which are exposed to strong UV radiation. The residual penetration, penetration attenuation index at $25^{\circ} \mathrm{C}$, and residual ductility of the asphalt were used as indicators to characterize the aging of asphalt, while the fracture energy method was used as a supplementary evaluation method.
\end{abstract}

Keywords: strong UV radiation; asphalt UV aging; physical property; rheological property

\section{Introduction}

The anti-aging performance of asphalt is the main factor affecting the quality and lifespan of asphalt pavement. The aging behavior of asphalt in the different structural layers of asphalt pavement is quite different [1-3]. While external temperature and traffic load are shared by all layers, solar radiation only affects the upper layer. Studies have shown that although ultraviolet (UV) radiation directly affects the asphalt surface, considering the diffusion of asphalt molecules after aging and the existence of voids in asphalt pavements, $\mathrm{UV}$ radiation can affect the surface to a depth of about $1 \mathrm{~cm}$ [4]. Aging causes the lowtemperature stiffness of the upper layer of the asphalt mixture to increase, often resulting in temperature shrinkage cracking [5]. UV rays, coupled with the impact of rain and snow, promote the deterioration of the road surface and seriously affect its durability [6]. Consequently, the aging effect of UV radiation on asphalt pavement materials cannot be ignored [7].

Scholars have carried out many studies on the UV aging of asphalt. Montepara used a self-developed UV aging chamber to study the chemical evolution of asphalt and the changes in its physical properties before and after UV aging. In addition, an attempt was made to establish a correspondence between laboratory exposure time and equivalent solar UV radiation time [8,9]. Bocci et al. investigated the effect of UV radiation on the short- and long-term aging of asphalt using a new UV standardized aging procedure in combination with rotating film oven tests and pressure aging vessels. The results showed that the effect of photochemical processes on the rheological parameters of asphalt can be quantified. UV aging could not be simulated by standard oxidative heat treatments performed in the laboratory [10]. Ye et al. established an indoor asphalt UV aging simulation system, and 
compared the performance of the asphalt materials after indoor and outdoor UV aging. Meanwhile, the mechanism of asphalt photo-oxidation under UV radiation conditions and the factors influencing the rate of asphalt photo-oxidation were explored. The results showed that this was a feasible method for studying the photooxidative aging of road asphalt in areas which experience strong UV radiation [11]. It was evident that UV aging has significant effects on the physical and chemical properties of asphalt [12,13]. During UV aging, light components in asphalt are transformed into heavy components, and the colloidal structure gradually transforms into gel-type [5,14]. Wu et al. found that asphalt UV aging is related to the intensity of the radiation and the thickness of the asphalt film. Generally, the stronger the UV radiation intensity and the thinner the asphalt film, the more significant the asphalt aging [15]. It is worth noting that the aging effect leads to an increase in viscosity and a decrease in fatigue resistance. Meanwhile, it has adverse effects on its high-, medium- and low-temperature rheology; among them, the adverse effect on low-temperature performance is the most significant $[5,16-18]$. Because the asphalt film of the asphalt mixture is thin, $\mathrm{UV}$ radiation has a greater impact on the surface of the asphalt mixture $[15,19]$. Therefore, scholars have also undertaken studies on the performance of asphalt mixtures after UV aging. Ma adopted two UV aging methods, i.e., indoor simulation and atmospheric exposure, to study the water stability of an asphalt mixture before and after aging through water immersion rutting test, freeze-thaw splitting test and water immersion Marshall test. The results showed that the water stability gradually decreased with an increase of UV aging time. It is most relevant to use the water immersion rutting and freeze-thaw splitting tests to evaluate the UV aging performance of asphalt mixtures [20]. Tong et al. conducted indoor accelerated UV aging tests on asphalt sand, and prepared asphalt mixtures to evaluate their UV aging performance. It was found that the low-temperature performance and fatigue resistance of the asphalt mixture decreased after UV aging [21]. Qian et al. treated asphalt materials under different water environments and UV radiation conditions, and studied their rheological properties and microstructures. The results showed that moisture can accelerate the UV aging process. Under the combined action of moisture and UV aging, the low-temperature anticracking performance of the asphalt mixture decreased. Also, compared with long-wave UV radiation, short-wave UV radiation leads to more significant aging [4].

The northwestern region of China, represented in the present study by Gansu Province, is located inland and has diverse climate types. Some areas have severe climate conditions and receive high levels of strong UV radiation [22]. In the Hexi Corridor area of Gansu Province, average annual sunshine hours have reached more than $2800 \mathrm{~h}[23,24]$. With the successful implementation of the "Western Development" and "One Belt, One Road" policies of the Chinese government, road construction in the northwest region has increased dramatically. However, the impact of climate on asphalt pavements in this area cannot be ignored. Under the combined action of UV light and oxygen, the aging of asphalt pavement materials accelerates, their stiffness modulus under low-temperature conditions increases significantly, and damage strain is reduced. It is easy to produce temperature shrinkage and cracking, which seriously affects the performance and service life of asphalt pavements $[6,25]$. The current research mainly focuses on analyzing the decay law of asphalt performance after accelerated aging by UV light. UV aging has a significant impact on asphalt performance, but due to different test conditions and mixed experimental equipment, the reproducibility of test results is limited. It is rare to find a standardized method or a suitable evaluation index with which to describe the UV aging level of asphalt. As such, it is impossible to provide a set of systematic evaluation methods for scientific research and practical engineering. Therefore, there is a genuine need for an asphalt UV aging evaluation system which is suitable for northwest China, including appropriate test methods and evaluation indicators.

To this end, Dunhuang City in the Hexi region of Gansu Province was taken as the study site. A variety of tests and analysis methods were used to study the performance changes of asphalt materials in this area under UV radiation, and a targeted asphalt UV 
aging evaluation method is proposed which could be of great significance for highway construction, as it could serve to improve the performance of asphalt pavements and extend their service life in areas which experience strong UV radiation. Firstly, based on the intensity of UV radiation in Dunhuang City, the appropriate indoor accelerated UV aging test conditions were determined. Secondly, based on the determined indoor accelerated UV aging test conditions, the conventional physical properties, rheological properties, and room temperature crack resistance of asphalt materials commonly used in the upper layer of asphalt pavement in this area after UV aging were analyzed. Subsequently, reliable evaluation indicators were chosen. Finally, combining the test results and existing specifications, a set of evaluation systems for asphalt UV aging in northwest China was established.

\section{Materials and Methods}

\subsection{Raw Materials}

\subsubsection{Base Asphalt}

The 80/100 pen grade base asphalt produced by Karamay Petrochemical Branch of PetroChina Co Ltd., 80/100 pen grade base asphalt produced by Sinopec Group, and $60 / 80$ pen grade base asphalt produced by SK HOLDINGS were used. For clarity, the three base asphalts are marked as 90-1, 90-2 and 70-1 in this study, respectively, and their technical indicators are shown in Table 1.

Table 1. Technical indicators of base asphalts.

\begin{tabular}{|c|c|c|c|c|c|c|}
\hline \multicolumn{2}{|c|}{ Technical Indicators } & $90-1$ & $90-2$ & Requirements & $70-1$ & Requirements \\
\hline \multicolumn{2}{|c|}{ Penetration $\left(25^{\circ} \mathrm{C}, 100 \mathrm{~g}, 5 \mathrm{~s}\right) /(0.1 \mathrm{~mm})$} & 88.4 & 80.2 & $80-100$ & 70.1 & $60-80$ \\
\hline \multicolumn{2}{|c|}{ Ductility $\left(5 \mathrm{~cm} / \mathrm{min}, 10^{\circ} \mathrm{C}\right) / \mathrm{cm}$} & $>100$ & $>100$ & $\geq 30$ & 56.9 & $\geq 25$ \\
\hline \multicolumn{2}{|c|}{ Softening point $/{ }^{\circ} \mathrm{C}$} & 46 & 51.1 & $\geq 44$ & 46.9 & $\geq 45$ \\
\hline \multicolumn{2}{|c|}{ Density $\left(25^{\circ} \mathrm{C}\right) /\left(\mathrm{g} / \mathrm{cm}^{3}\right)$} & 0.998 & 1.006 & - & 1.018 & - \\
\hline \multirow{3}{*}{$\begin{array}{l}\text { Rotating film oven test } \\
\qquad\left(163^{\circ} \mathrm{C}, 85 \mathrm{~min}\right)\end{array}$} & Mass loss $/ \%$ & -0.23 & 0.31 & \pm 0.8 & 0.26 & \pm 0.8 \\
\hline & Residual penetration ratio/\% & 77 & 70 & $\geq 57$ & 70 & $\geq 61$ \\
\hline & Residual ductility $\left(10^{\circ} \mathrm{C}\right) / \mathrm{cm}$ & 32 & 22 & $\geq 8$ & 11.8 & $\geq 6$ \\
\hline
\end{tabular}

\subsubsection{SBS Modified Asphalt}

Two SBS I-C modified asphalts, produced by Karamay Petrochemical Branch of PetroChina Co Ltd. and Sinopec Group, were selected, and are labeled herein as SBS-1 and SBS-2, respectively. The technical indicators of SBS modified asphalt are shown in Table 2.

Table 2. Technical indicators of SBS modified asphalt.

\begin{tabular}{|c|c|c|c|c|}
\hline \multicolumn{2}{|c|}{ Technical Indicators } & SBS-1 & SBS-2 & Requirements \\
\hline \multicolumn{2}{|c|}{ Penetration $\left(25^{\circ} \mathrm{C}, 100 \mathrm{~g}, 5 \mathrm{~s}\right) /(0.1 \mathrm{~mm})$} & 75 & 73.3 & $60-80$ \\
\hline \multicolumn{2}{|c|}{ Ductility $\left(5 \mathrm{~cm} / \mathrm{min}, 10^{\circ} \mathrm{C}\right) / \mathrm{cm}$} & 65.5 & 66.7 & 55 \\
\hline \multicolumn{2}{|c|}{ Softening point $/{ }^{\circ} \mathrm{C}$} & 59 & 37.1 & $\geq 30$ \\
\hline \multicolumn{2}{|c|}{ Density $\left(25^{\circ} \mathrm{C}\right) /\left(\mathrm{g} / \mathrm{cm}^{3}\right)$} & 1.018 & 1.101 & - \\
\hline \multirow{3}{*}{$\begin{array}{l}\text { Rotating film oven } \\
\text { test }\left(163^{\circ} \mathrm{C}, 85 \mathrm{~min}\right)\end{array}$} & Mass loss $/ \%$ & -0.14 & 0.06 & $\leq 1$ \\
\hline & Residual penetration ratio/ $\%$ & 79 & 72 & $\geq 60$ \\
\hline & Residual ductility $\left(10^{\circ} \mathrm{C}\right) / \mathrm{cm}$ & 37 & 26 & $\geq 20$ \\
\hline
\end{tabular}

\subsection{Indoor Accelerated UV Aging Test System}

The indoor light aging simulation test was selected in this study, as its acceleration factor can reach 5 to 10 times that of outdoor tests, meaning that the light aging performance of asphalt can be studied in a much shorter period. The indoor accelerated UV aging test system mainly includes a UV light source, temperature control system, and UV radiation test system. 


\subsubsection{Light Source}

Through a literature review [26-31], it was determined that there are currently three main types of light sources used in UV aging tests, namely xenon, fluorescent UV and highpressure mercury lamps. Among them, fluorescent UV and xenon lamps are often used for research on plastic products, while in most studies on asphalt UV aging, high-pressure mercury lamps were used. Thus, this study selected a straight tube high-pressure mercury lamp with a power of $1000 \mathrm{~W}$ as the light source of the test system. The device and its parameters are shown in Figure 1 and Table 3.
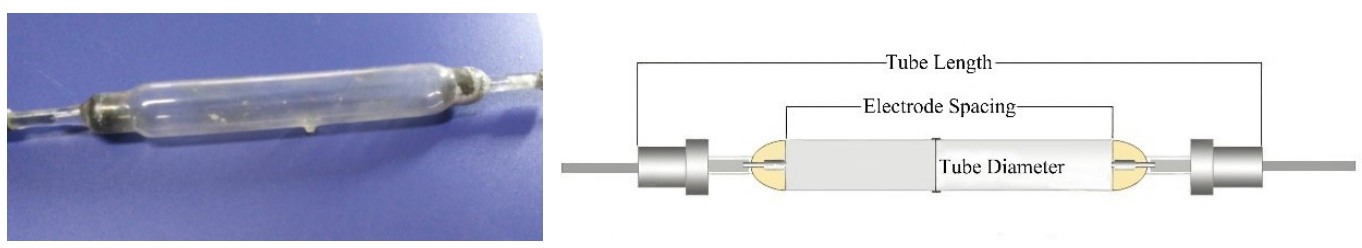

Figure 1. Straight tube high pressure mercury lamp used in testing.

Table 3. Parameters of straight tube high-pressure mercury lamp.

\begin{tabular}{ccccc}
\hline Power/KW & $\begin{array}{c}\text { Tube } \\
\text { Length/mm }\end{array}$ & $\begin{array}{c}\text { Electrode } \\
\text { Spacing/mm }\end{array}$ & $\begin{array}{c}\text { Tube } \\
\text { Diameter/mm }\end{array}$ & Voltage/V \\
\hline 1 & 300 & 200 & 28 & 220 \\
\hline
\end{tabular}

\subsubsection{Test Temperature}

In summer, the surface temperature of asphalt pavements can reach $60^{\circ} \mathrm{C}$. Consequently, $60^{\circ} \mathrm{C}$ was selected as the temperature for the accelerated UV aging test. Figure 2 depicts an indoor accelerated UV aging environment chamber equipped with a suitable temperature control system.

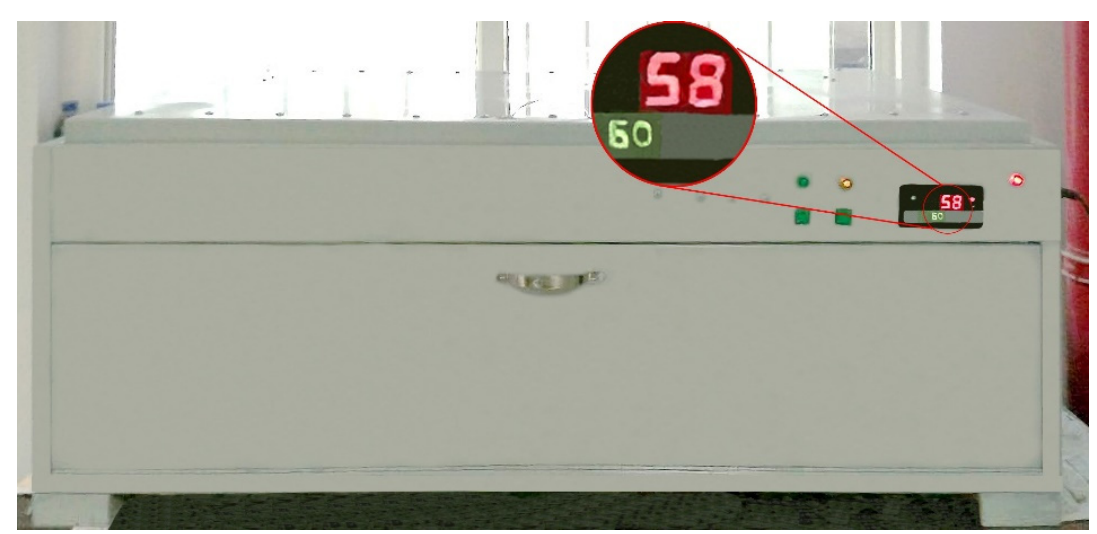

Figure 2. Indoor accelerated UV aging environment chamber.

\subsubsection{UV Irradiance}

In order to ensure accuracy, two types of UV irradiance meters were used at the same time. After measuring the UV irradiance at 15 uniformly distributed positions in the test chamber, the final UV irradiance was determined to be $152.7 \mathrm{~W} / \mathrm{m}^{2}$.

\subsubsection{Test Time}

The UV irradiance acceleration multiple conversion algorithm was used to determine the test time, as shown in Equation (1).

$$
\mathrm{N}=\frac{\mathrm{Ux}}{\mathrm{U}}
$$


where $\mathrm{N}$ is the acceleration multiple of UV irradiance; Ux is the measured indoor UV irradiance, $\mathrm{W} / \mathrm{m}^{2}$; and $\mathrm{U}$ is the average outdoor daily average $\mathrm{UV}$ irradiance, $\mathrm{W} / \mathrm{m}^{2}$.

On the basis of a large number of previous analyses, Dunhuang City, Gansu Province, was taken as the research area, and the daily average maximum irradiance of this area was measured. The resulting value was converted to correlate to the indoor UV irradiance. The conversion results are shown in Table 4 .

Table 4. Correspondence between outdoor and indoor UV irradiation time.

\begin{tabular}{ccc}
\hline Outdoor Time/Month & Outdoor UV Irradiation Time/h & Indoor UV Irradiation Time/h \\
\hline 2 & 480 & 32 \\
4 & 960 & 64 \\
6 & 1440 & 96 \\
8 & 1920 & 128 \\
10 & 2400 & 160 \\
12 & 2880 & 192 \\
\hline
\end{tabular}

\subsubsection{Sample Preparation}

The asphalt sample container used in the indoor accelerated UV aging test is shown in Figure 3a. The sampling and preparation methods of base or modified asphalt were in accordance with T0601-2011 and T0602-2011 in JTG E20-2011 [32]. First, asphalt with a mass of $11.30 \pm 0.5 \mathrm{~g}$ was poured into the sample container, and then heated to $135 \pm 1{ }^{\circ} \mathrm{C}$, ensuring that it was evenly spread in the container. The asphalt sample used for the indoor accelerated UV aging test is shown in Figure $3 b$.
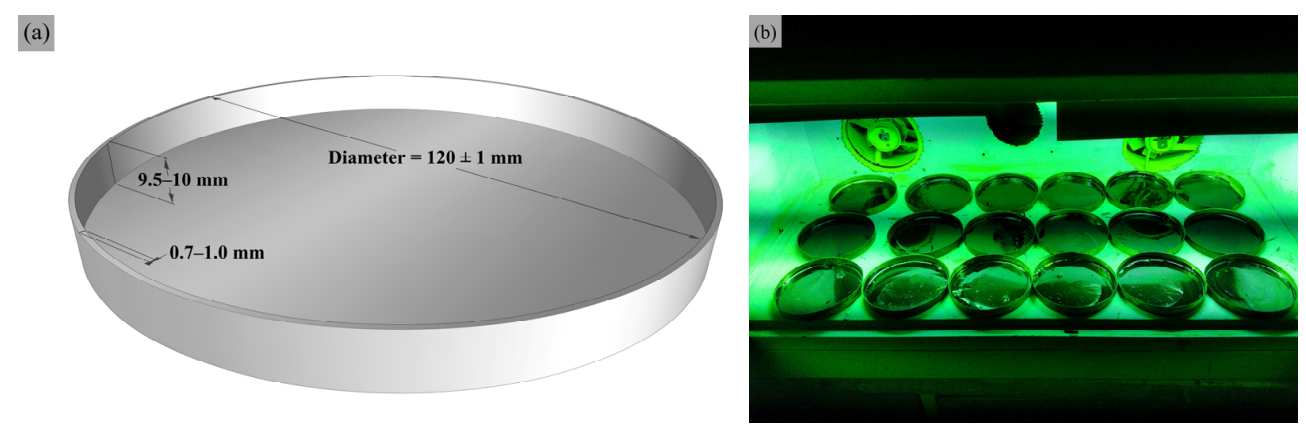

Figure 3. (a) Sample container; (b) asphalt sample used for the indoor accelerated UV aging test.

\subsection{Experimental Methods}

In accordance with the T0610-2011 in JTG E20-2011 standards [32], a rotating film oven test (RTFOT) was used for the short-term aging of the asphalt. The test temperature was $163 \pm 0.5^{\circ} \mathrm{C}$ and the aging time was $85 \mathrm{~min}$. A pressure aging vessel (PAV) was used. The pressure used in the test was $2.1 \pm 0.1 \mathrm{MPa}$, the temperature was $100 \pm 0.1^{\circ} \mathrm{C}$, and the aging time was $20 \mathrm{~h}$.

The indoor accelerated UV aging test system described in Section 2.2 was used. Thermal and UV aging are distinct from one another. In order to more accurately evaluate the UV aging performance of asphalt, this study conducted a single UV aging test, and the samples used were not subjected to heat aging treatment.

Penetration, ductility, and softening point tests were carried out on asphalts aged in different ways. The test temperature of the penetration test was $25^{\circ} \mathrm{C}$. In the ductility test, the test temperatures of base asphalt and modified asphalt were $10{ }^{\circ} \mathrm{C}$ and $5{ }^{\circ} \mathrm{C}$, respectively, and the tensile rate was $5 \mathrm{~cm} / \mathrm{min}$.

In accordance with the ASTM D7175 [33] and ASTM D6648 [34] standards, dynamic shear rheology (DSR) tests and bending beam rheology (BBR) tests were carried out on various asphalts before and after aging. In the DSR test, the base asphalt test temperature 
was $25-65{ }^{\circ} \mathrm{C}$, the modified asphalt test temperature was $40-65^{\circ} \mathrm{C}$, and the load frequency was $10 \mathrm{rad} / \mathrm{s}$.

A WDW-100 electronic tensile testing machine produced by the MTS Corporation (USA) was used. In accordance with related literature [35,36], the test temperature was set to $15^{\circ} \mathrm{C}$, and the tensile rate was $500 \mathrm{~mm} / \mathrm{min}$.

\section{Results and Discussion}

\subsection{Physical Properties}

\subsubsection{Penetration}

Figure 4 shows the results of the penetration test of asphalt at $25^{\circ} \mathrm{C}$ under different aging methods. The penetration of the asphalt which underwent UV32h aging was equivalent to the value after RTFOT aging, while the penetration of the asphalt after PAV aging test was equivalent to that of UV96h aging asphalt. It is generally believed that the PAV test achieves five years of road surface aging. Consequently, after a certain period, the degradation of asphalt caused by UV aging is greater than that caused by PAV aging. The penetration of asphalt changes most in the early stage of the aging process. The penetration attenuation rate of the five asphalts was the fastest at UV32h, and gradually decreased after UV96h. Under indoor UV conditions, the penetration attenuation rates of various asphalts under UV64h, UV96h and UV192h were the same.

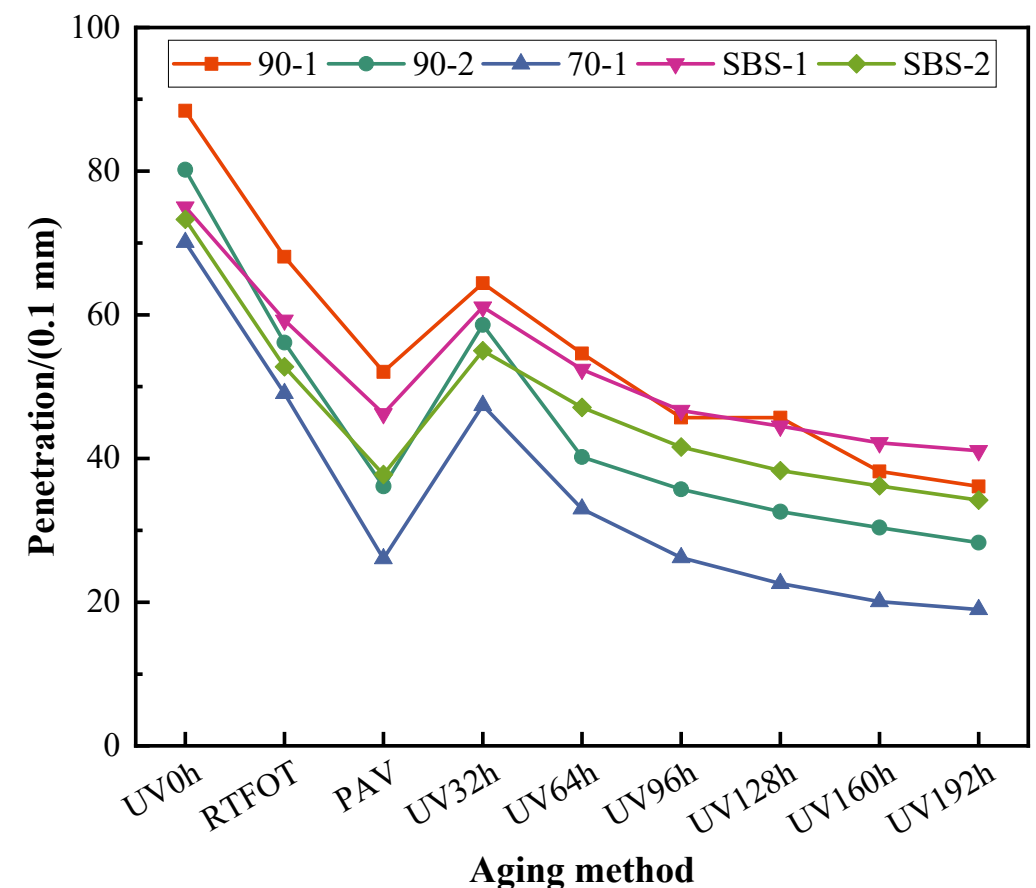

Figure 4. Penetration of asphalt at $25^{\circ} \mathrm{C}$ under different aging methods.

The penetration attenuation rate of UV96h and the penetration of UV96h and UV192h are shown in Table 5. It can be seen that for asphalt with a penetration attenuation rate of more than 50\% in UV96h, when the UV aging reached $192 \mathrm{~h}$, the penetration rate dropped below 30, indicating that the asphalt had a greater probability of subsequent cracking. Therefore, the penetration attenuation rate of UV96h is defined as the penetration attenuation index, as shown in Equation (2). UV aging can be restricted by this index.

$$
\mathrm{U}_{\mathrm{p} 96}=\frac{\mathrm{P}_{0}-\mathrm{P}_{96} \times 100}{\mathrm{P}_{0}}
$$

where $\mathrm{U}_{\mathrm{p} 96}$ is the penetration attenuation index of UV96h; $\mathrm{P}_{0}$ is the penetration at $25{ }^{\circ} \mathrm{C}$ before asphalt aging; and $\mathrm{P}_{96}$ is the penetration of asphalt at $25^{\circ} \mathrm{C}$ after $96 \mathrm{~h} \mathrm{UV}$ aging. 
Table 5. Penetration attenuation rate of UV96h and penetration of UV96h and UV192h.

\begin{tabular}{cccc}
\hline \multirow{2}{*}{ Asphalt Type } & UV96h Penetration & \multicolumn{2}{c}{ Penetration/(0.1 mm) } \\
\cline { 3 - 4 } & Attenuation Rate/\% & UV96h & UV192h \\
\hline $90-1$ & 48.3 & 45.7 & 36.1 \\
$90-2$ & 55.5 & 35.7 & 28.3 \\
$70-1$ & 62.6 & 26.2 & 19 \\
SBS-1 & 37.7 & 46.7 & 41.1 \\
SBS-2 & 43.2 & 41.6 & 34.2 \\
\hline
\end{tabular}

\subsubsection{Ductility}

Ductility is often used to evaluate the low-temperature performance of asphalt. Figure 5 shows the results of the ductility test of asphalt under different aging methods. It can be seen from the results that the ductility attenuation of the base asphalt after aging was much greater than that of the modified asphalt, indicating that the aging resistance of the modified asphalt was better. The asphalt ductility of UV32h was equivalent to the value after RTFOT aging, while the asphalt ductility of UV96h was equivalent to that of PAV aging, i.e., basically the same as the change trend for penetration.

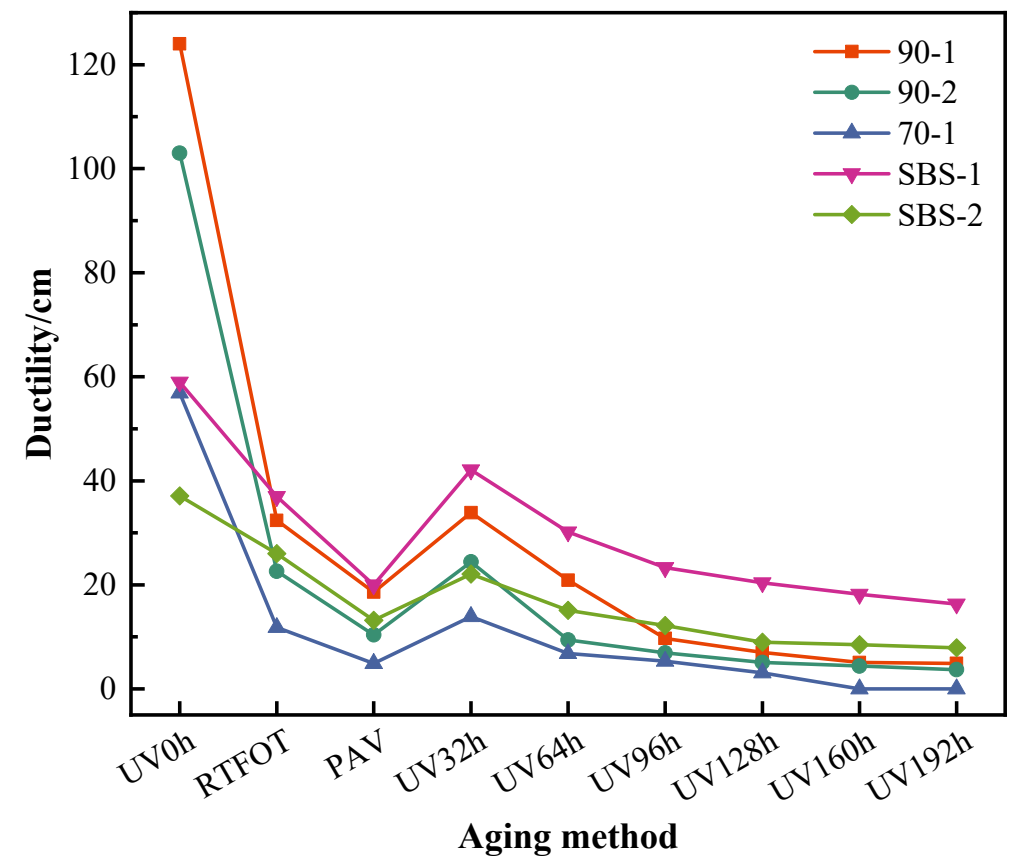

Figure 5. Ductility of asphalt under different aging methods.

Currently, the ductility value is generally used as the requirement for minimum ductility of asphalt after aging. JTG F40-2004 [37] requires that the residual ductility of $80 / 100$ and $60 / 80$ pen grade base asphalt after RTFOT at $10^{\circ} \mathrm{C}$ is not less than $8 \mathrm{~cm}$ and $6 \mathrm{~cm}$, respectively, while the residual ductility of SBS I-C modified asphalt at $5{ }^{\circ} \mathrm{C}$ after RTFOT is not less than $20 \mathrm{~cm}$. It can be seen from Figure 5 that the 90-1, 90-2, 70-1, SBS-1, and SBS-2 asphalts did not meet the specification requirements at UV128h, UV96h, UV96h, UV160h, and UV64h, respectively. The ductility of various asphalts was shown to have a maximum attenuation rate at UV32h, and to basically stabilize after UV96h. Observing the ductility values of five asphalts under UV96h, it was found to be more intuitive to directly use the ductility value as a technical index to evaluate the low-temperature performance of asphalt after UV aging. Combined with the above analysis, the residual ductility value after UV96h was selected as the low-temperature performance index for evaluating asphalt after UV aging. For areas which experience strong UV radiation, under the premise that the ductility index of the asphalt after the RTFOT test is required, the ductility value of the 
asphalt after the UV aging test for $96 \mathrm{~h}$ met the index value of the ductility of the asphalt after the RTFOT test in JTG F40-2004 [37].

\subsubsection{Softening Point}

Softening point is a commonly used index to evaluate the high-temperature performance of asphalt. Figure 6 shows the softening point test results of asphalt under different aging methods. The softening point of base asphalt showed an increasing trend as the degree of aging increased. The softening points of base asphalt after RTFOT aging and PAV aging were equivalent to those of UV32h and UV96h, respectively. In addition, the softening point of SBS-1 modified asphalt tended to increase during RTFOT aging and UV aging, but decreased after PAV aging. The softening point of SBS-2 modified asphalt gradually increased under the thermal aging test conditions, but showed a decreasing trend under UV aging. Consequently, the softening point index was not predictable after UV aging, and is therefore not suitable for performance evaluations of asphalt after UV aging.

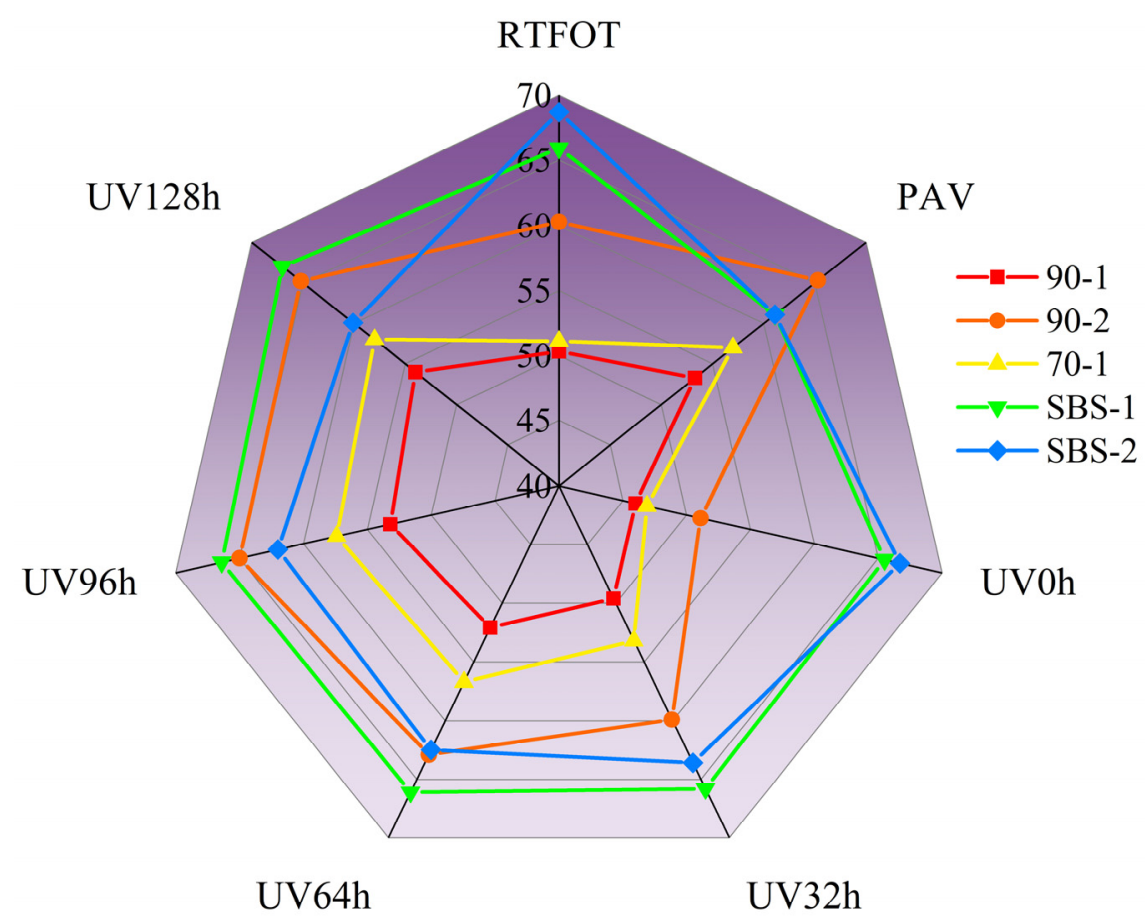

Figure 6. The softening point of asphalt under different aging methods.

\subsection{Rheological Properties}

The DSR and BBR tests proposed in the American SHRP Asphalt Binder Road Performance Specification are usually used to evaluate the high- and low-temperature rheological properties of asphalt. From the results of the previous section, it can be seen that the physical properties of 90-1 base asphalt and SBS-2 modified asphalt were better than those of other types. As a consequence, they were taken as research objects, representing base asphalt and modified asphalt, respectively, to explore the sensitivity of asphalt rheological properties to accelerated indoor UV aging.

\subsubsection{Dynamic Shear Rheological Test}

The complex shear modulus $\mathrm{G}^{*}$ is the ratio of stress to strain under dynamic load; it is an important parameter that characterizes the dynamic viscoelasticity of asphalt $[8,38,39]$. The phase angle $\delta$ reflects the ratio and degree of influence of the viscous to elastic components in viscoelasticity [40-42]; the larger the phase angle, the higher the proportion of viscous components in the asphalt. 
Figure 7 shows the DSR test results of 90-1 base asphalt under different aging conditions. In Figure $7 a$, the $G^{*}$ of asphalt decreases with increasing temperature. The $G^{*}$ of the original asphalt (UVOh) was the smallest in the entire temperature range, and the $\mathrm{G}^{*}$ of the asphalt of UV96h was the largest at $25^{\circ} \mathrm{C}$, followed by UV128h aging and PAV aging. In the range of 25 to $45^{\circ} \mathrm{C}$, the $\mathrm{G}^{*}$ of asphalt varied greatly. The $\mathrm{G}^{*}$ value in the interval of 50 to $65^{\circ} \mathrm{C}$ can be used to distinguish different aging degrees of asphalt. At this time, the order of the asphalt $G^{*}$ is UV128h $>$ UV96h $>$ PAV $>$ UV64h $>$ UV32h $>$ UV0h; the greater the $G^{*}$ in this temperature range, the greater the degree of asphalt aging.

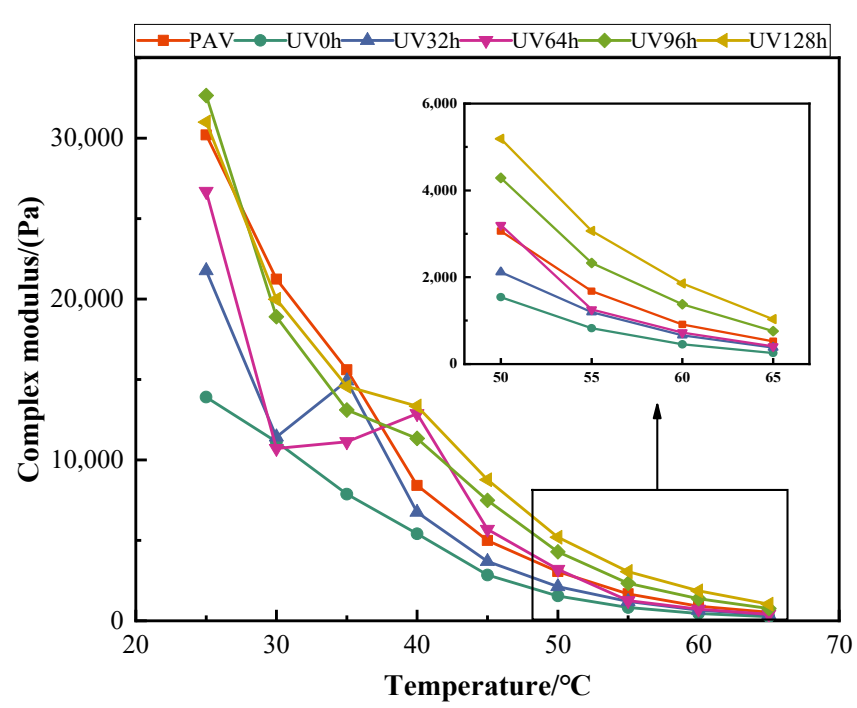

(a)

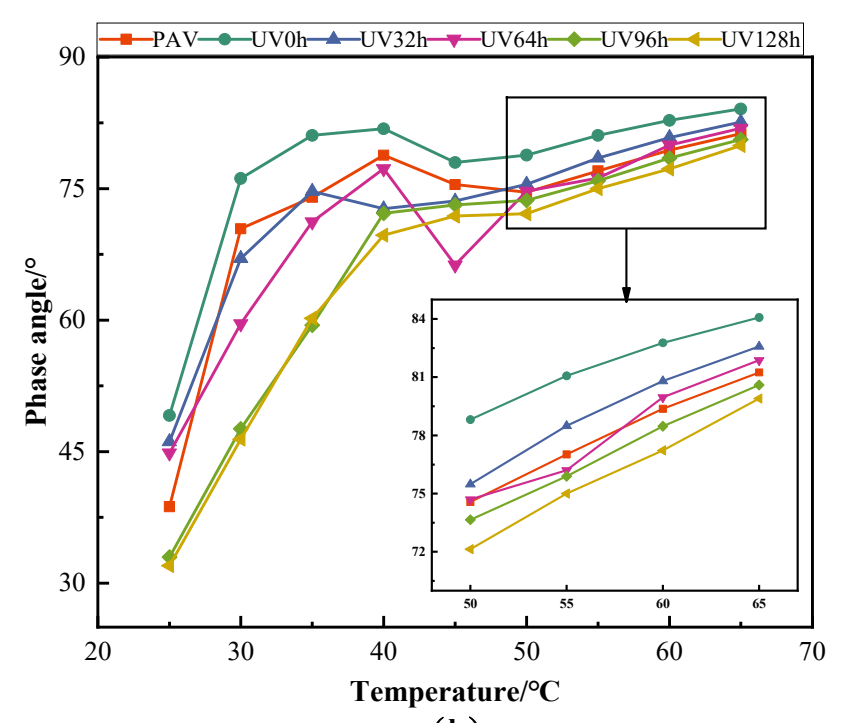

(b)

Figure 7. DSR test results of 90-1 base asphalt under different aging conditions: (a) complex modulus; (b) phase angle.

In addition, the $\delta$ of the base asphalt increases with increase of temperature. The $\delta$ of the original asphalt was the largest in the entire temperature range, while that of UV128h was the smallest. It can be seen from Figure $7 \mathrm{~b}$ that the $\delta$ varied greatly in the range of 25 to $45{ }^{\circ} \mathrm{C}$, which is consistent with the change trend of the $\mathrm{G}^{*}$ in Figure $7 \mathrm{a}$. The reason was that in this temperature range, the viscoelasticity of asphalt is particularly significant. When the temperature was higher than $45^{\circ} \mathrm{C}$, the $\delta$ of the asphalt gradually increased and tended to be flat. In the range of 50 to $65^{\circ} \mathrm{C}$, the order of asphalt $\delta$ was UV0h $>$ UV32h $>$ UV64h $>$ PAV > UV96h > UV128h, which was basically consistent with the trend of the influence of aging methods on asphalt penetration.

Figure 8 shows the DSR test results of SBS-2 modified asphalt under different aging conditions. It can be seen that the $\mathrm{G}^{*}$ of modified asphalt decreased with the increase of temperature. At $50^{\circ} \mathrm{C}$, the order of $\mathrm{G}^{*}$ was UV128h $>$ UV96h $>$ PAV $>$ UV32h $>$ UV64h $>$ UV0h. At $65{ }^{\circ} \mathrm{C}$, the order of $\mathrm{G}^{*}$ was UV128h $>$ UV96h $>$ PAV $>$ UV64h $>$ UV32h $>$ UV0h. As the degree of aging increased, the $\mathrm{G}^{*}$ of modified asphalt increased, and the $\mathrm{G}^{*}$ at UV96h was greater than that of PAV aging. The higher the asphalt aging degree, the more intense the volatilization of light components and the oxidation and polymerization of other components in the system, which means that the harder the asphalt, the higher the $G^{*}$ value [43]. This indicates that UV aging has a more destructive effect on the modified asphalt. 


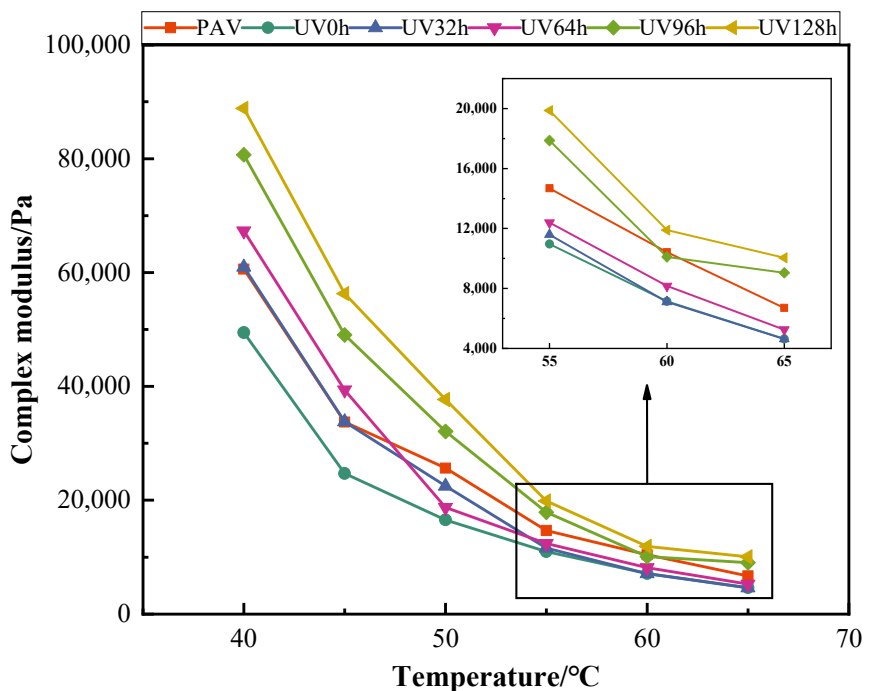

(a)

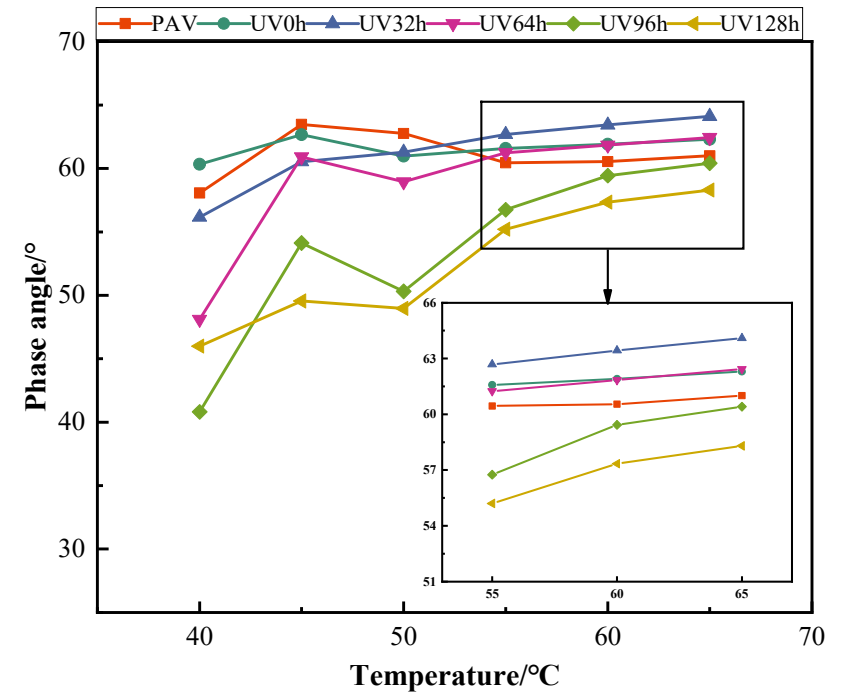

(b)

Figure 8. DSR test results of SBS-2 modified asphalt under different aging conditions: (a) complex modulus; (b) phase angle.

In addition, in the entire temperature range, the $\delta$ of the modified asphalt showed an overall increasing trend, which was consistent with the base asphalt. At $40^{\circ} \mathrm{C}$, the order of the $\delta$ of the modified asphalt was UV0h $>$ PAV $>$ UV32h $>$ UV64h $>$ UV128h $>$ UV96h. At $40-55{ }^{\circ} \mathrm{C}$, the $\delta$ of modified asphalt changed greatly, and the $\delta$ of asphalt after UV32h and PAV aging even exceeded that of unaged modified asphalt. As the temperature continued to rise, the change trend of the $\delta$ gradually stabilized. As shown in Figure $8 b$, in the interval of $55-65{ }^{\circ} \mathrm{C}$, the order of $\delta$ was UV32h $>$ UV0h $>$ UV64h $>$ PAV $>$ UV96h $>$ UV128h, that is, the $\delta$ of modified asphalt increased at the initial stage of UV aging (UV32h). As the degree of aging increased, it gradually became smaller, which was inconsistent with the change trend of $\delta$ of base asphalt after aging.

By analyzing the dynamic shear rheological properties of 90-1 base asphalt and SBS-2 modified asphalt, it was concluded that the phase angle $\delta$ and dynamic shear modulus $\mathrm{G}^{*}$ of the DSR test in the high-temperature range $\left(>50{ }^{\circ} \mathrm{C}\right)$ could be used to characterize the changes in the performance of asphalt after aging. The results showed that UV aging has a greater impact on asphalt rheology than PAV aging. The effect of different aging conditions on the performance of modified asphalt is more complicated than that of base asphalt, i.e., after adding modifiers, the colloidal system of modified asphalt changes. UV aging may promote the decomposition of related polymer substructures into smaller copolymers, which helps to improve the relative performance of polymer-modified asphalt $[44,45]$.

\subsubsection{Bending Beam Rheological Test}

Through the BBR test, the flexural creep stiffness $S$ and the creep rate $m$ could be obtained, and the low-temperature crack resistance of asphalt could subsequently be evaluated. SHRP requires that the $S$ at the $60 \mathrm{~s}$ does not exceed $300 \mathrm{MPa}$, and that $m$ is not less than $0.3[46,47]$.

The results of the BBR test are shown in Figure 9. It can be seen that the $S$ of SBS-2 modified asphalt at UV32h and UV64h decreased compared with that before aging, while the $S$ of 90-1 base asphalt after aging showed an increasing trend. The $m$ of SBS-2 modified asphalt increased in UV32h, while that of 90-1 base asphalt decreased after aging. A larger $S$ and smaller $m$ indicate reduced low-temperature crack resistance. Compared with the SBS-2 modified asphalt, the 90-1 base asphalt had a greater increase in $S$ and a greater decrease in $m$, indicating that the low-temperature crack resistance of the modified asphalt after aging was better than that of the base asphalt $[48,49]$. 


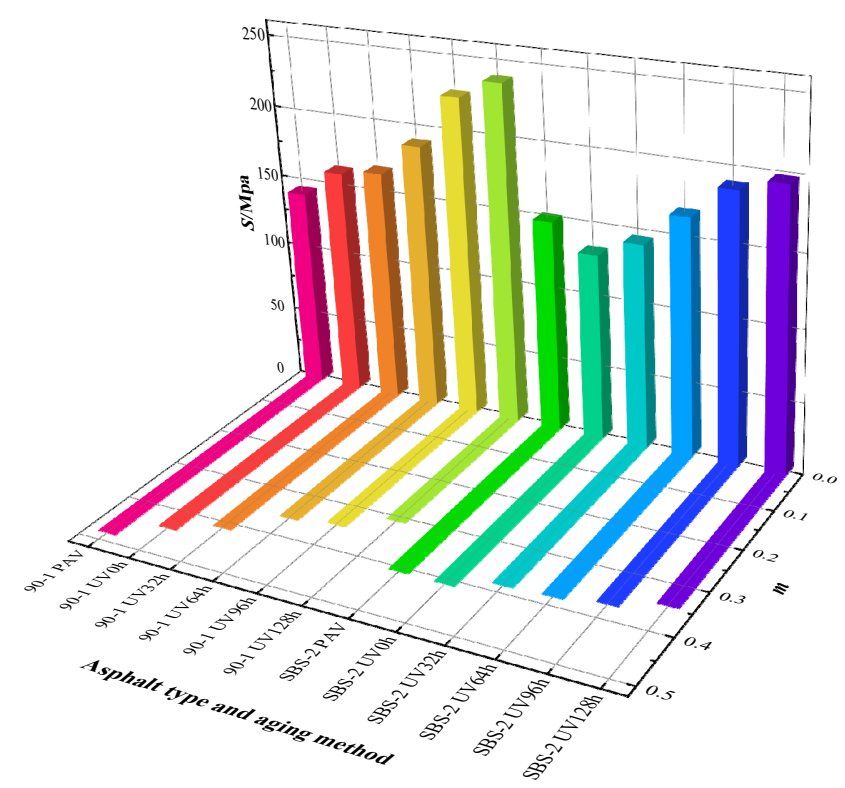

Figure 9. BBR test results of asphalts under different aging conditions.

Through an analysis of the BBR test, it could be seen that UV aging reduced the low-temperature crack resistance of asphalt; the longer the UV aging time, the more severe the degradation of asphalt performance. In contrast to 90-1 base asphalt, SBS-2 modified asphalt had reduced $S$ after UV32h and UV64h UV aging. It is worth noting that the BBR test can effectively reflect the low-temperature performance of the asphalt binder, but there are exceptions. For some modified asphalt, the BBR test does not reflect the deformability of this type of binder, and other test methods are required [50].

\subsection{Full-Section Fracture Energy Test}

In this study, the new, full-face fracture energy test method developed by Niu et al. [35] was adopted. This method can be used to evaluate the true stress-true strain of asphalt on the central full-fracture surface in a normal temperature range, and can subsequently accurately determine the full-face fracture energy. In addition, the test can also characterize the fatigue performance of asphalt, which makes up for the inadequacy of existing test methods to accurately obtain the true stress and strain of the nonlinear viscoelastic or plastic modified asphalt. Therefore, 90-1 base asphalt and SBS-2 modified asphalt were selected, and the full-face fracture energy method was used before and after UV aging. Figures 10 and 11 are the true stress-true strain curves and full-face fracture energy of asphalt under different aging methods.

According to Figure 11, it can be seen that the fracture energy of SBS-2 modified asphalt in different aging states was greater than that of 90-1 base asphalt. The order of the fracture energy of 90-1 base asphalt in different aging states was U32h $>$ PAV $>$ U64h $>$ U96h $>$ U128h $>$ U160h. At the beginning of UV aging of asphalt, the rupture energy density decreased greatly. When the UV aging exceeded 96h, the fracture energy of the base asphalt tended to be stable. The change trend of fracture energy of SBS-2 modified asphalt in different aging states was similar to that of base asphalt. The difference is that the fracture energy declining trend of the SBS-2 modified asphalt tended to be flat after UV128h.

From the above test results, it can be seen that the fracture energy of modified asphalt and base asphalt at UV160h were 0.752 and $0.483 \mathrm{MPa}$, respectively. The higher the fracture energy of the material, the better the crack resistance [51], indicating that the crack resistance of SBS-2 modified asphalt after aging was better than that of base asphalt. Comparing the results of the ductility and BBR tests, it can be concluded that the asphalt crack resistance obtained by the full-face fracture energy method correlated well with these two tests. This shows that the full-face fracture energy method can be used not 
only to evaluate the anticracking performance of asphalt at room temperature, but also to predict the low-temperature anticracking performance of asphalt. In addition, since the test temperature of this method was normal, it can also be used to evaluate the fatigue performance of asphalt in a normal temperature range.

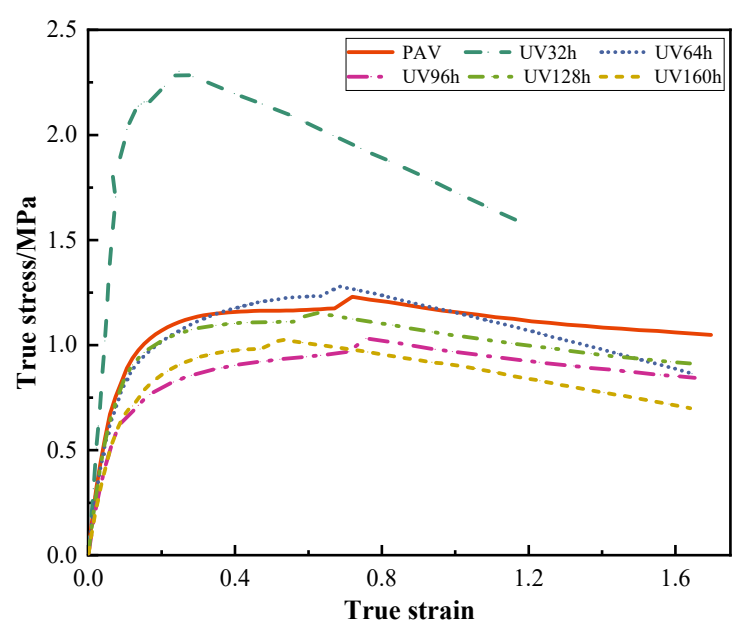

(a)

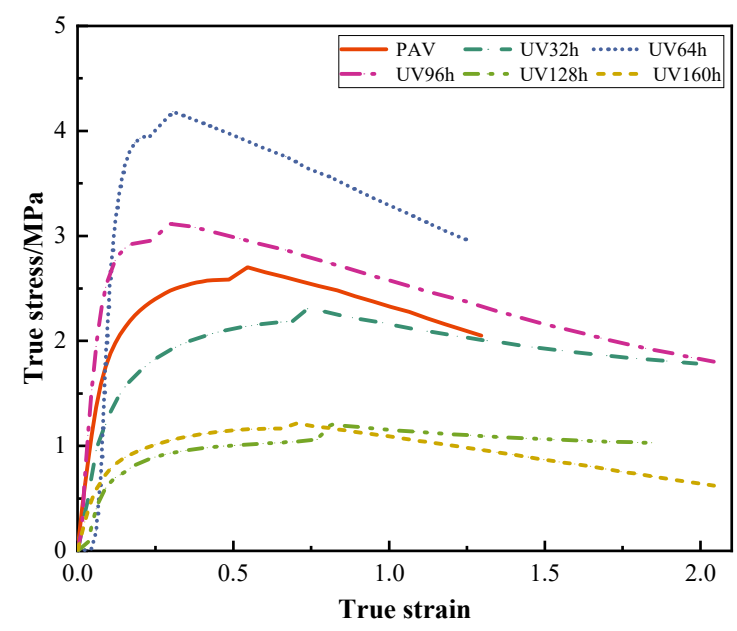

(b)

Figure 10. The true stress-true strain curves of asphalts under different aging methods: (a) 90-1 base asphalt, (b) SBS-2 modified asphalt.

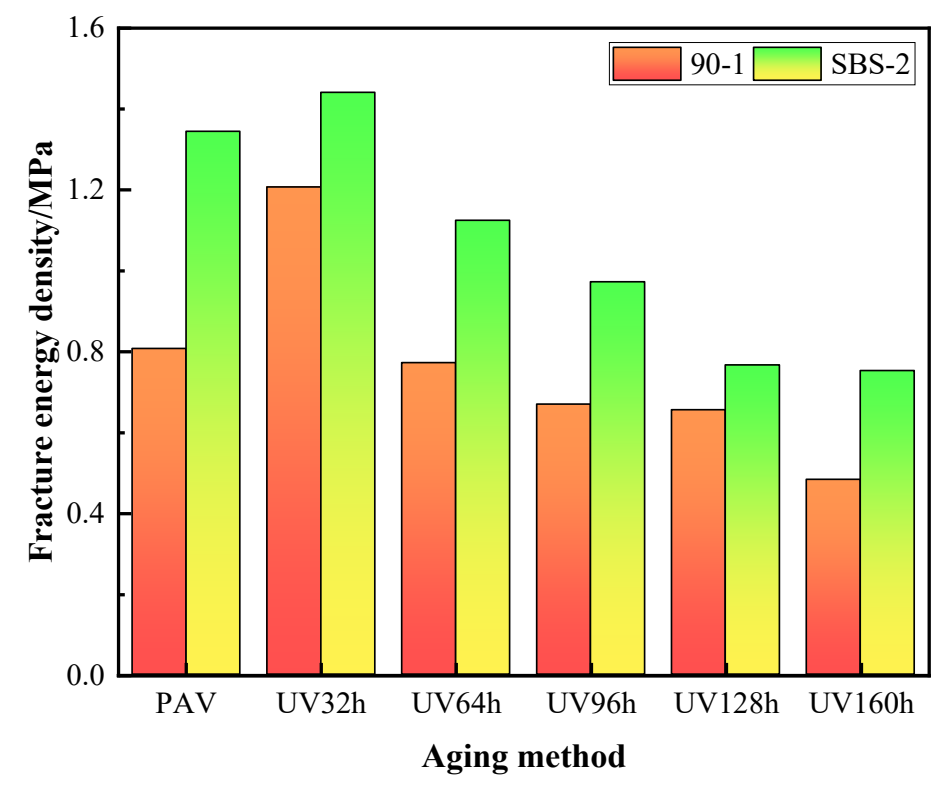

Figure 11. The fracture energy density of asphalt under different aging methods.

\subsection{Establishment of Asphalt UV Aging Evaluation System in Strong Radiation Area}

The asphalt UV aging evaluation system used in northwest China includes two key parts: one is the UV aging test method, and the other is the technical indicators and technical requirements based on the test method. For the formulation of the UV aging test method, based on a full analysis of the road surface temperature and the UV irradiance of the month with the strongest UV radiation in Dunhuang City in the early stage, it was formulated in reference to the current relevant specifications for asphalt RTFOT aging, PAV aging, and plastic material light aging tests and other technical specifications. The technical indicators and requirements were based on the evaluation of the above-mentioned regulatory indicators and fracture energy. 


\subsubsection{Formulation of the Test Method}

As shown in Section 2.2, the indoor accelerated UV aging test used a high-pressure mercury lamp as the UV light source, and the UV irradiation environment was maintained at $60{ }^{\circ} \mathrm{C}$. The specifications of the sample container and the sample preparation requirements used in the test are the same as those described in Section 2.2.5.

Under the above test conditions, through the use of various asphalts in the UV aging test under different UV irradiation times, it can be seen that the asphalt performance degradation rate in the early stage of UV aging was high. Generally, after indoor UV aging for $96 \mathrm{~h}$, which is equivalent to 6-8 months of outdoor UV aging, the asphalt UV aging rate slowed down. Consequently, this time was set as the indoor accelerated UV aging standard time under the research test environment. According to $1 \mathrm{~W}=3.6 \mathrm{KJ} / \mathrm{h}$, the corresponding UV irradiance at this time was calculated to be about $152.7 \mathrm{~W} / \mathrm{m}^{2} \times 96 \mathrm{~h}=14,659 \mathrm{~W} / \mathrm{m}^{2}$, and the amount of UV radiation was about $152.7 \mathrm{~W} / \mathrm{m}^{2} \times 96 \mathrm{~h} \times 3.6 \mathrm{KJ} / \mathrm{h}=52,773 \mathrm{KJ} / \mathrm{m}^{2}$. Based on this, the indoor accelerated aging time required when the cumulative received $\mathrm{UV}$ radiation of the asphalt was $52,773 \mathrm{KJ} / \mathrm{m}^{2}$ could be calculated, as shown in the following Equation (3):

$$
\mathrm{t}=\frac{14659}{\mathrm{UV0}}
$$

where $t$ is the indoor accelerated aging time required when the accumulated $\mathrm{UV}$ radiation of the asphalt is $52,773 \mathrm{KJ} / \mathrm{m}^{2}$ at $60{ }^{\circ} \mathrm{C}$, h; and UV0 is the measured UV irradiance of the test chamber, $\mathrm{W} / \mathrm{m}^{2}$.

\subsubsection{Determination of Technical Indicators and Technical Requirements}

Through the analysis of the sensitivity and applicability of the index values of various asphalts after UV aging, it can be seen that the softening point index cannot be reliably determined after UV aging. The $\mathrm{G}^{*}$ and $\delta$ of the DSR test are suitable for evaluating the high-temperature rheological properties of the base asphalt, while the UV aging mainly affects fatigue and low-temperature performance. The $S$ and $m$ of the BBR test can be used to characterize the low-temperature performance of the base asphalt. However, for some modified asphalts, these tests are unsuitable and the equipment required for the BBR test is complicated, which limits their use in engineering applications at present.

The dynamic equation of asphalt aging was used to predict the change trend of the asphalt sensitivity index over 1 to 5 years. Meanwhile, referring to the selection and scope of requirements of technical indicators after asphalt aging according to the current specifications, indicators with high sensitivity to UV aging, convenient operation, and predictability for later aging are preferred. These indicators are widely used as asphalt UV aging technical indicators in northwest China, and the technical indicator requirements are formulated in combination with the relevant specifications and the test results of this research.

\section{Establishment of the Dynamic Equation of Asphalt UV Aging}

The asphalt aging process can be characterized by the dynamic aging equation, as shown in Equation (4) [23]. According to the test results of penetration and ductility at different UV aging times in Section 3.1, the dynamic equation of asphalt UV aging can be obtained, and the penetration and ductility values at other aging times can be estimated using this equation. The dynamic equation of asphalt UV aging is shown in Table 6.

$$
\mathrm{Y}(\mathrm{t})=\frac{\mathrm{my}_{0}}{[1+(\mathrm{m}-1)] \mathrm{e}^{-\mathrm{nt}}}
$$

where $Y(t)$ is the index value of asphalt after UV aging for time $t ; m$ is the ratio of asphalt index $\mathrm{Y}$ at time $\mathrm{t}$ to the initial time; and $\mathrm{n}$ is a measure of the rate of increase (or decrease) of asphalt performance $Y(t)$ for a given $m$ value.

It can be seen from Table 7 that after $96 \mathrm{~h}$ of indoor UV aging, the penetration attenuation rate slows down, which is the reason why this time is used as the standard UV aging 
time. According to the regulation in JTG-F41-2008 [32], the penetration of asphalt materials used for regeneration must be higher than 20, that is, when the asphalt has undergone long-term aging, if the penetration is less than 20 , it indicates that the aging limit has been reached, and that this cannot be used for asphalt regeneration. Combining these facts with the data presented in Figure 12, when the penetration attenuation rate of UV96h was higher than $50 \%$, the indoor UV aging for $960 \mathrm{~h}$, that is, the outdoor aging for 60 months (5 years), the asphalt penetration rate dropped below 20. As a consequence, the penetration attenuation rate of UV96h was taken, i.e., $50 \%$, which has been determined as one of the evaluation indexes of asphalt after ultraviolet aging.

Table 6. Dynamic equation of asphalt UV aging.

\begin{tabular}{|c|c|c|c|c|c|}
\hline $\begin{array}{c}\text { Asphalt } \\
\text { Type }\end{array}$ & Evaluation Index & m & $\mathbf{n}$ & Dynamic Aging Equation & $\mathbf{R}^{2}$ \\
\hline \multirow{2}{*}{$90-1$} & Penetration $\left(25^{\circ} \mathrm{C}, 0.1 \mathrm{~mm}\right)$ & 0.3038 & 0.0052 & $Y(t)=26.9 /\left(1-0.6962 \times 10^{-0.0053 t}\right)$ & 0.9987 \\
\hline & Ductility $\left(10^{\circ} \mathrm{C}, \mathrm{cm}\right)$ & -0.1135 & -0.0072 & $Y(t)=-5.0 /\left(1-1.1135 \times 10^{0.00727 t}\right)$ & 0.9989 \\
\hline \multirow{2}{*}{$90-2$} & Penetration $\left(25^{\circ} \mathrm{C}, 0.1 \mathrm{~mm}\right)$ & 0.2432 & 0.0049 & $Y(t)=19.5 /\left(1-0.97568 \times 10^{-0.004951 t}\right)$ & 0.9883 \\
\hline & Ductility $\left(10^{\circ} \mathrm{C}, \mathrm{cm}\right)$ & -0.0779 & -0.0069 & $\mathrm{Y}(\mathrm{t})=-8.0 /\left(1-1.07794 \times 10^{1.07794 \mathrm{t}}\right)$ & 0.9988 \\
\hline \multirow{2}{*}{$70-1$} & Penetration $\left(25^{\circ} \mathrm{C}, 0.1 \mathrm{~mm}\right)$ & 0.0663 & 0.0012 & $\mathrm{Y}(\mathrm{t})=4.7 /\left(1-0.9987 \times 10^{-0.00122 \mathrm{t}}\right)$ & 0.9963 \\
\hline & Ductility $\left(10^{\circ} \mathrm{C}, \mathrm{cm}\right)$ & - & - & - & - \\
\hline \multirow{2}{*}{ SBS-1 } & Penetration $\left(25^{\circ} \mathrm{C}, 0.1 \mathrm{~mm}\right)$ & 0.4821 & 0.0079 & $Y(t)=36.2 /\left(1-0.992 \times 10^{-0.00799 t}\right)$ & 0.9983 \\
\hline & Ductility $\left(5^{\circ} \mathrm{C}, \mathrm{cm}\right)$ & -0.0170 & -0.0002 & $\mathrm{Y}(\mathrm{t})=-1.0 /\left(1-10^{0.00024 \mathrm{t})}\right.$ & 0.9959 \\
\hline \multirow{2}{*}{ SBS-2 } & Penetration $\left(25^{\circ} \mathrm{C}, 0.1 \mathrm{~mm}\right)$ & 0.4086 & 0.0078 & $Y(t)=30.0 /\left(1-0.992 \times 10^{-0.00783 t}\right)$ & 0.9997 \\
\hline & Ductility $\left(5^{\circ} \mathrm{C}, \mathrm{cm}\right)$ & 0.0277 & 0.0006 & $Y(t)=1.0 /\left(1-0.9994 \times 10^{-0.00064 t)}\right.$ & 0.9959 \\
\hline
\end{tabular}

Proposal of Penetration

Based on the dynamic equation of asphalt UV aging, the penetration of asphalt under other UV aging times could be determined, as shown in Figure 12. Table 7 shows the penetration rate of each index at different aging times.

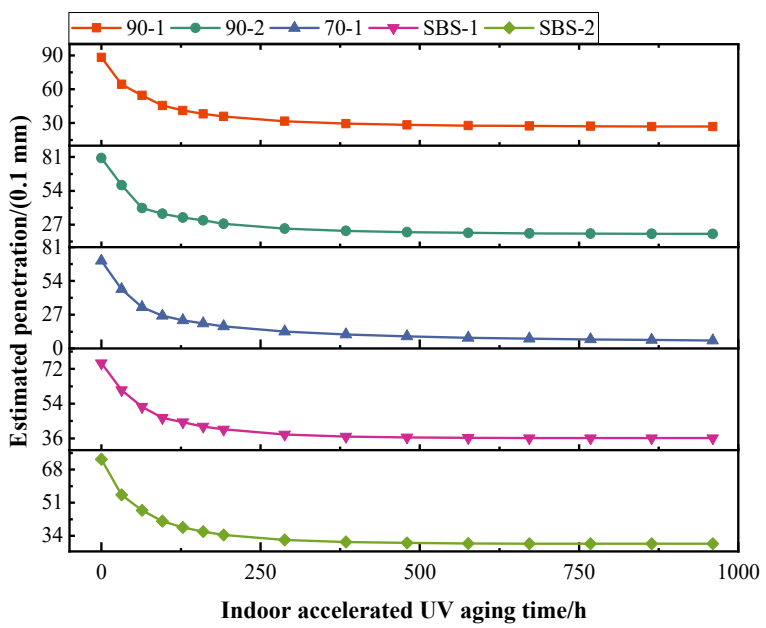

Figure 12. The estimated value of penetration after UV aging.

In addition, the absolute value of the penetration of UV96h had a greater impact on the penetration of later aging. For $80 / 100$ pen grade base asphalt, when the penetration of UV96h was less than 45 , the estimated value of UV960h was less than 30 . The penetration of $60 / 80$ pen grade base asphalt after UV96h was already less than 30 , so after long-term aging, the estimated residual penetration was only 6.5. When the penetration of SBS I-C polymer modified asphalt was greater than 40 after UV96h, the predicted value of UV960h was greater than 30 . Based on this, it can be concluded that, on the one hand, $60 / 80$ pen grade base asphalt is not suitable for use in northwest China, and on the other hand, the 
absolute penetration value of UV96h has a certain predictability for the change of asphalt performance after long-term UV aging. Therefore, the absolute value of penetration of UV96h is also used as an evaluation index of asphalt UV aging.

Table 7. Attenuation rate of asphalt penetration.

\begin{tabular}{ccccc}
\hline \multirow{2}{*}{ Asphalt Type } & \multicolumn{4}{c}{ Penetration Attenuation Rate/\% } \\
\cline { 2 - 5 } & UV32h & UV64h & UV96h & UV192h \\
\hline $90-1$ & 27.15 & 38.24 & 48.30 & 56.79 \\
$90-2$ & 26.93 & 49.88 & 55.49 & 62.09 \\
$70-1$ & 32.38 & 52.92 & 62.62 & 71.33 \\
SBS-1 & 18.53 & 30.13 & 37.73 & 43.73 \\
SBS-2 & 24.97 & 35.74 & 43.25 & 50.61 \\
\hline
\end{tabular}

Based on the above analysis, using UV96h, that is, under the test conditions of this study, the $25^{\circ} \mathrm{C}$ residual penetration and penetration attenuation index when the cumulative UV radiation was about $52,773 \mathrm{KJ} / \mathrm{m}^{2}$ were used at the same time, which placed a double constraint on the UV aging performance of the asphalt.

Proposal of Ductility

Based on the dynamic equation of asphalt UV light aging, the ductility value of asphalt under other UV aging times could be obtained. The ductility at $10^{\circ} \mathrm{C}$ of the base asphalt and that at $5{ }^{\circ} \mathrm{C}$ of the modified asphalt were used. The results are shown in Figure 13 .

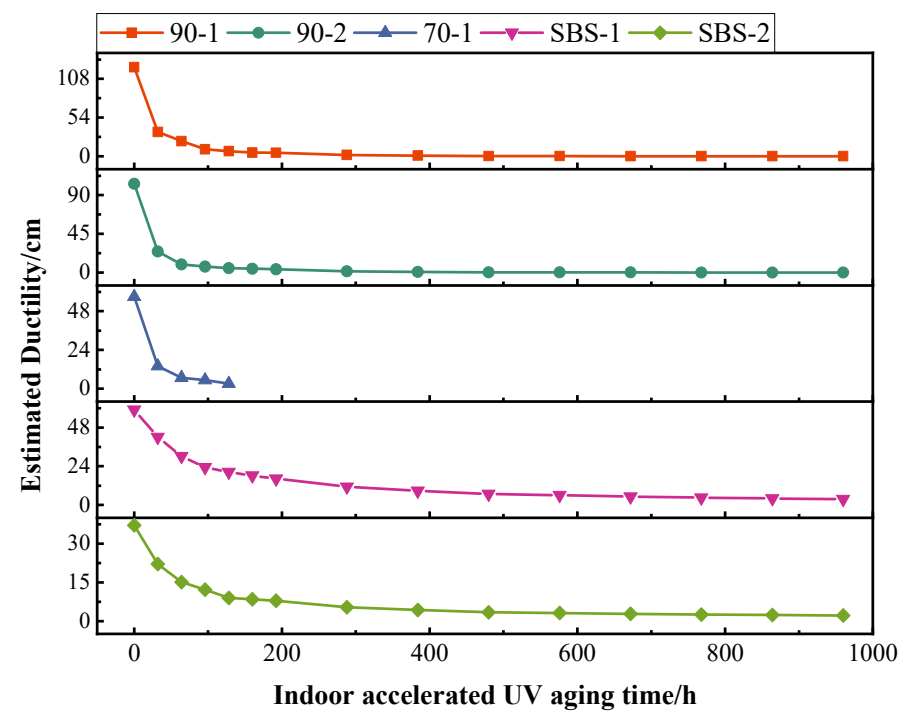

Figure 13. Estimated values of ductility after UV aging.

Figure 13 show that the decrease in the ductility of asphalt showed a slowing trend after UV96h. The value of 60/80 pen grade base asphalt after UV aging for 1 year could no longer be accurately measured. The estimated value of $80 / 100$ pen grade base asphalt at UV960h tended to 0 , indicating that the aging of $80 / 100$ pen grade base asphalt by UV aging reached the limit. The estimated values of SBS modified asphalt at UV960h were $3.61 \mathrm{~cm}$ and $2.17 \mathrm{~cm}$, i.e., better than the corresponding value for base asphalt. This shows that UV aging has a great impact on the low-temperature performance of asphalt, and that low-temperature ductility is highly sensitive to UV aging. According to the analysis in Section 3.1.2, the ductility ratio index currently proposed in MH/T 5010-2017 [52] is not applicable to the experimental results of this study. Consequently, according to an analysis in this section, the residual ductility ratio was used as one of the indicators of asphalt after UV aging. In addition, it can be seen from Section 3.1.2 that the impact of UV96h on the low-temperature ductility of asphalt was greater than that of RTFOT aging. 
Final determination of the ductility index value of the asphalt should refer to the ductility index value after RTFOT aging of the asphalt in JTG F40-2004 [37].

\section{Full-Section Fracture Energy}

According to the calculation results of fracture energy density presented in Section 3.3, it can be seen that the fracture energy density of SBS-2 modified asphalt in different aging states was greater than that in 90-1 base asphalt. Meanwhile, the order of fracture energy of 90-1 base asphalt in different aging states was the same as that of SBS-2 modified asphalt. It is worth mentioning that the fracture energy density at the initial stage of UV aging decreased greatly. When the UV aging was greater than 96h, the fracture energy of the base asphalt tended to be stable, while the decline of the fracture energy of the SBS-2 modified asphalt tended to be gentle after UV128h. As a consequence, the crack resistance and normal temperature fatigue resistance of asphalt could be evaluated from a mechanical point of view based on the fracture energy value. In the evaluation method of this study, the fracture energy method was used as a supplementary evaluation method after UV aging. For asphalt with little difference in penetration attenuation index, residual penetration, and residual ductility, the asphalt with higher fracture energy density was preferred.

\section{Determination of Technical Indicators and Required Values}

According to the analysis mentioned above, $60 / 80$ pen grade base asphalt is unsuitable for the upper layer material of asphalt pavements in northwest China. Therefore, the technical indicators developed in this study were mainly for 80/100 pen grade base and SBS I-C modified asphalts. Tables 8 and 9 show the aging technical indicators and requirements of $80 / 100$ pen grade base asphalt and SBS I-C modified asphalt for use in northwest China. The method for determining the technical requirement value was based on the test analysis of this study and those of other researchers, and was combined with the relevant specifications [32,52]. It is worth noting that, because this study conducted a single UV aging test, the samples used were not subjected to heat aging treatment. Consequently, the asphalt underwent the UV aging test proposed in this study with the objective of meeting the RTFOT aging index.

Table 8. Technical indicators and requirements for UV aging of 80/100 pen grade base asphalt.

\begin{tabular}{|c|c|c|}
\hline Technical Indicators & Requirements & Test Method \\
\hline \multicolumn{2}{|c|}{ After RTFOT test } & \multirow[b]{2}{*}{ T0610 } \\
\hline Mass loss $/ \%$ & $\leq \pm 0.8$ & \\
\hline Residual penetration $\left(25^{\circ} \mathrm{C}\right) /(0.1 \mathrm{~mm})$ & $\geq 57$ & T0604 \\
\hline Residual ductility $\left(10^{\circ} \mathrm{C}\right) / \mathrm{cm}$ & $\geq 8$ & T0605 \\
\hline \multicolumn{2}{|c|}{ After accelerated indoor UV aging test } & \multirow[b]{2}{*}{ Section 2.2} \\
\hline Mass loss $/ \%$ & $\leq \pm 0.8$ & \\
\hline Penetration attenuation index $\left(25^{\circ} \mathrm{C}\right) / \%$ & $\geq 50$ & \multirow{2}{*}{ T0604 } \\
\hline Residual penetration $\left(25^{\circ} \mathrm{C}\right) /(0.1 \mathrm{~mm})$ & $\geq 45$ & \\
\hline Residual ductility $\left(10^{\circ} \mathrm{C}\right) / \mathrm{cm}$ & $\geq 8$ & T0605 \\
\hline
\end{tabular}

Table 9. Technical indicators and requirements for UV aging of SBS I-C modified asphalt.

\begin{tabular}{ccc}
\hline Technical Indicators & Requirements & Test Method \\
\hline Mass loss $/ \%$ & & T0610 \\
After RTFOT test & $\leq \pm 1$ & T0604 \\
Residual penetration $\left(25^{\circ} \mathrm{C}\right) /(0.1 \mathrm{~mm})$ & $\geq 60$ & T0605 \\
Residual ductility $\left(5^{\circ} \mathrm{C}\right) / \mathrm{cm}$ & $\geq 20$ & Section 2.2 \\
After accelerated indoor UV aging test & $\leq \pm 1$ & T0604 \\
Mass loss $/ \%$ & $\geq 50$ & T0605 \\
Penetration attenuation index $\left(25^{\circ} \mathrm{C}\right) / \%$ & $\geq 40$ & \\
Residual penetration $\left(25^{\circ} \mathrm{C}\right) /(0.1 \mathrm{~mm})$ & $\geq 20$ & \\
Residual ductility $\left(5^{\circ} \mathrm{C}\right) / \mathrm{cm}$ & & \\
\hline
\end{tabular}

Note: For Tables 8 and 9, when the gap between the conventional indexes of asphalt is small after UV aging, the full-section fracture energy method is required, and the asphalt with high fracture energy density is preferred. 


\section{Conclusions}

In this study, the appropriate indoor UV accelerated aging test conditions were determined based on the conditions present in Dunhuang City. Through a series of tests, the physical properties, rheological properties, and room temperature crack resistance of asphalt after UV aging were investigated, and reliable evaluation indexes were selected to devise an asphalt UV aging evaluation system which would be suitable for use in northwest China. The main conclusions are as follows:

(1) The indoor accelerated UV aging test applied in this study was shown to be able to accurately simulate the aging evolution process of asphalt under UV light irradiation.

(2) Long-term UV aging has more adverse effects on asphalt physical properties, rheological properties, and crack resistance than RTFOT and PAV aging, having the most significant impact on the low-temperature crack resistance of asphalt.

(3) The $60 / 80$ pen grade base asphalt was found to be unsuitable for asphalt pavement construction in northwest China. When the cumulative received UV radiation of the asphalt was $52,773 \mathrm{KJ} / \mathrm{m}^{2}$, the residual penetration, penetration attenuation rate at $25^{\circ} \mathrm{C}$, and the residual ductility of $80 / 100$ pen grade base asphalt and SBS I-C modified asphalt were used as technical indicators.

(4) The full-section fracture energy method was used as a supplementary evaluation method. When the conventional indicators meet the standard and the difference is small, an asphalt material with a large fracture energy density is preferred.

Author Contributions: Conceptualization, L.Z.; methodology, L.Z.; software, Y.Z.; validation, Y.Z.; formal analysis, L.Z.; investigation, L.Z.; resources, L.Z.; data curation, B.L.; writing-original draft preparation, L.Z.; writing-review and editing, L.Z. and Y.Z.; visualization, Y.Z.; supervision, B.L.; project administration, L.Z.; funding acquisition, L.Z. All authors have read and agreed to the published version of the manuscript.

Funding: This research was funded by National Key R\&D Program of China (Grant Number: 2018YFB1600100).

Institutional Review Board Statement: Not applicable.

Informed Consent Statement: Not applicable.

Data Availability Statement: All data, models, and code generated or used during the study appear in the submitted article.

Conflicts of Interest: No conflict of interest exits in the submission of this manuscript, and manuscript is approved by all authors for publication. We would like to declare on behalf of my co-authors that the work described was original research that has not been published previously, and not under consideration for publication elsewhere, in whole or in part. All the authors listed have approved the manuscript that is enclosed.

\section{References}

1. Wang, F.S.; Zhang, L.; Zhang, X.S.; Li, H.C.; Wu, S.P. Aging Mechanism and Rejuvenating Possibility of SBS Copolymers in Asphalt Binders. Polymers 2020, 12, 92. [CrossRef]

2. Wang, G.R.; Rao, D.M.; Li, K.T.; Lin, Y.J. UV Blocking by Mg-Zn-Al Layered Double Hydroxides for the Protection of Asphalt Road Surfaces. Ind. Eng. Chem. Res. 2014, 53, 4165-4172. [CrossRef]

3. Xiang, L.; Tu, J.; Cheng, J.; Que, G.H. Outdoor aging of road asphalt and SBS modified asphalt. Front. Chem. Sci. Eng. 2011, 5, 35-42. [CrossRef]

4. Chen, Z.H.; Zhang, H.L.; Duan, H.H. Investigation of ultraviolet radiation aging gradient in asphalt binder. Constr. Build. Mater. 2020, 246, 118501. [CrossRef]

5. Yu, H.N.; Bai, X.P.; Qian, G.P.; Wei, H.; Gong, X.B.; Jin, J.; Li, Z.J. Impact of Ultraviolet Radiation on the Aging Properties of SBS-Modified Asphalt Binders. Polymers 2019, 11, 1111. [CrossRef] [PubMed]

6. Zaumanis, M.; Mallick, R.B.; Frank, R. Evaluation of different recycling agents for restoring aged asphalt binder and performance of 100\% recycled asphalt. Mater. Struct. 2015, 48, 2475-2488. [CrossRef]

7. Durrieu, F.; Farcas, F; Mouillet, V. The influence of UV aging of a Styrene/Butadiene/Styrene modified bitumen: Comparison between laboratory and on-site aging. Fuel 2007, 86, 1446-1451. [CrossRef] 
8. $\quad$ Li, Y.; Wu, S.; Liu, Q.; Dai, Y.; Li, C.; Li, H.; Nie, S.; Song, W. Aging degradation of asphalt binder by narrow-band UV radiations with a range of dominant wavelengths. Constr. Build. Mater. 2019, 220, 637-650. [CrossRef]

9. Zeng, W.; Wu, S.; Pang, L.; Chen, H.; Hu, J.; Sun, Y.; Chen, Z. Research on Ultra Violet (UV) aging depth of asphalts. Constr. Build. Mater. 2018, 160, 620-627. [CrossRef]

10. Li, Y.; Feng, J.; Yang, F.; Wu, S.; Liu, Q.; Bai, T.; Liu, Z.; Li, C.; Gu, D.; Chen, A.; et al. Gradient aging behaviors of asphalt aged by ultraviolet lights with various intensities. Constr. Build. Mater. 2021, 295, 123618. [CrossRef]

11. Ye, F.; Huang, P. Establishment of Asphalt Ultraviolet Aging Simulation System. J. Build. Mater. 2005, 8, 567-571.

12. Yu, H.N.; Shen, S.H.; Qian, G.P.; Gong, X.B. Packing Theory and Volumetrics-Based Aggregate Gradation Design Method. J. Mater. Civ. Eng. 2020, 32, 04020110. [CrossRef]

13. Zadshir, M.; Ploger, D.; Yu, X.K.; Sangiorgi, C.; Yin, H.M. Chemical, thermophysical, rheological, and microscopic characterisation of rubber modified asphalt binder exposed to UV radiation. Road Mater. Pavement Des. 2020, 21, S123-S139. [CrossRef]

14. Zhang, Y.H.; Wei, H.; Dai, Y.H. Influence of Different Aging Environments on Rheological Behavior and Structural Properties of Rubber Asphalt. Materials 2020, 13, 3376. [CrossRef] [PubMed]

15. Wu, S.P.; Pang, L.; Mo, L. UV and Thermal Aging of Pure Bitumen-comparison Between Laboratory Simulation and Natural Exposure Aging. Road Mater. Pavement Des. 2008, 9, 103-113. [CrossRef]

16. Fang, J.M.; Tu, J.S. Effect of ultraviolet (UV) aging on rheology properties and microstructure of polyurethane (PU) modified asphalt. Mater. Res. Express 2019, 6, 125318. [CrossRef]

17. Li, H.L.; Tong, P.P.; Zhang, X.J.; Lin, X.X.; Li, B. Influence of Ultraviolet and Oxygen Coupling Aging on Rheological Properties and Functional Group Index of Warm Mix Asphalt Binder. Materials 2020, 13, 4216. [CrossRef] [PubMed]

18. Xie, X.; Li, H.; Duan, J.; Li, G.; Tong, S. Influence of the Mineral Powder Content on the Asphalt Aging Resistance in High-Altitude Areas Based on Indoor Ul-traviolet Light Tests. Materials 2020, 13, 754. [CrossRef]

19. Tia, M.; Ruth, B.; Charal, C. Investigation of Original and In-Service Asphalt Properties for the Development of Improved Specifications-Final Phase of Testing and Analysis; University of Florida: Gainesville, FL, USA, 1988.

20. Ma, L. Research on Water Stability of Ultraviolet Aging Asphalt Mixture. Highw. Eng. 2014, 39, 160-169.

21. Tong, S.; Li, H.; Wang, C. Research on Asphalt Mixture Ultraviolet Light Aging Evaluation Index. J. Highw. Transp. Sci. Technol. 2014, 31, 16-20.

22. Liu, H.; Hu, B.; Zhang, L.; Zhao, X.J.; Shang, K.Z.; Wang, Y.S.; Wang, J. Ultraviolet radiation over China: Spatial distribution and trends. Renew. Sust. Energ Rev. 2017, 76, 1371-1383. [CrossRef]

23. Kang, H.; Tan, X.; Ji, X. Aging Equation of SBS Modified Asphalt and Its Application. J. Wuhan Univ. Technol. $2019,33,95-99$.

24. Zhang, H.; Chen, Z.; Xu, G.; Shi, C. Physical, rheological and chemical characterization of aging behaviors of thermochromic asphalt binder. Fuel 2018, 211, 850-858. [CrossRef]

25. Fernandez-Gomez, W.D.; Quintana, H.A.R.; Daza, C.E.; Lizcano, F.A.R. The effects of environmental aging on Colombian asphalts. Fuel 2014, 115, 321-328. [CrossRef]

26. Rubber, Vulcanized-Test Method of Resistance to Artificial Weathering (Fluorescent UV Lamp); GB/T 16585-1996. 1996. Available online: http://openstd.samr.gov.cn/bzgk/gb/newGbInfo?hcno=7BB9019E278E8BE83DCBE13AB5ACE733 (accessed on 28 October 1996).

27. Ultraviolet High-Pressure Mercury Lamp; QB/T 2988-2008. 2008. Available online: http://hbba.sacinfo.org.cn/stdDetail/dbfcf7 81846cb11378d2d9af27948ec1 (accessed on 16 June 2008).

28. Method of Measurement of Ultraviolet Irradiance and Electrical Characteristic of Tubular Ultraviolet High-Pressure Mercu-Ry Lamp; QB/T 2989-2008. 2008. Available online: http://hbba.sacinfo.org.cn/stdDetail/79a4abb75df8e90f38c6d46421aa63cd (accessed on 16 June 2008).

29. Test Method for in Accelerated Weathering Building Materials; GB/T 16259-2008. 2008. Available online: http:/ / openstd.samr. gov.cn/bzgk/gb/newGbInfo?hcno=6E8A308D0F3CA656FDBBF901B4FA3AB3 (accessed on 4 May 2008).

30. Plastics-Methods of Exposure to Laboratory Light Sources. Part 2: Xenon-Arc Sources; GB/T 16422.2-2014. 2014. Available online: http:/ / openstd.samr.gov.cn/bzgk/gb/newGbInfo?hcno=42D41178025F1102F2E398C3C1B86403 (accessed on 8 July 2014).

31. Rubber, Vulcanized-Test Method for Artificial Weathering (Carbon-Arc Lamp); GB/T 15255-2015. 2015. Available online: http:/ / openstd.samr.gov.cn/bzgk/gb/newGbInfo?hcno=3FA043B124DF92DCF130412E38A3D554 (accessed on 15 May 2015).

32. Standard Test Methods of Bitumen and Bituminous Mixtures for Highway Engineering; JTG E20-2011. 2011. Available online: http:/ / std.samr.gov.cn/hb/search/stdHBDetailed?id=8B1827F23F43BB19E05397BE0A0AB44A (accessed on 4 July 2017).

33. International, A. Standard Test Method for Determining the Rheological Properties of Asphalt Binder Using a Dynamic Shear Rheometer; ASTM D7175. 2015. Available online: https:/ /www.astm.org/Standards/D7175.htm (accessed on 31 December 2015).

34. International, A. Standard Test Method for Determining the Flexural Creep Stiffness of Asphalt Binder Using the Bending Beam RheomeTer (BBR); ASTM D6648. 2008. Available online: https://www.astm.org/search/fullsite-search.html?query=ASTM\%20D6648\& (accessed on 31 December 2016).

35. Niu, T.Y.; Roque, R.; Lopp, G.A. Development of a binder fracture test to determine fracture energy properties. Road Mater. Pavement Des. 2014, 15, 219-238. [CrossRef]

36. Zhang, Z.; Sun, J.; Huang, Z.; Wang, F.; Jia, M.; Lv, W.; Ye, J. A laboratory study of epoxy/polyurethane modified asphalt binders and mixtures suitable for flexible bridge deck pavement. Constr. Build. Mater. 2021, 274, 122084. [CrossRef] 
37. Technical Specification for Construction of Highway Asphalt Pavements; JTG F40-2004. 2004. Available online: https://www. jygglj.com/upload/2016/08/26/2016-08-26-18-10-42-1357388530.pdf (accessed on 4 September 2004).

38. Jamieson, I.L.; Moulthrop, J.S.; Jones, D. SHRP results on binder-aggregate adhesion and resistance to stripping. In The Asphalt Yearbook; Institute of Asphalt Technology: Bathgate, UK, 1995.

39. Chari, C.T.; Ruth, B.E.; Tia, M. Evaluation of age hardening on asphalts and mixtures. J. Assoc. Asph. Paving Technol. 1990, 59, 176-239.

40. Liao, G.; Huang, X. Anti-ultraviolet aging tests of asphalts adapting to environment in Tibetan Plateau of China. J. Southeast Univ. (Engl. Ed.) 2008, 24, 503-507.

41. Wang, J.; Tan, Y.; Xue, Z. Analysis on property changes of neat and modified asphalt under ultraviolet aging. In Proceedings of the 18th ASCE Engineering Mechanics Division Conference, Blacksburg, VA, USA, 3-6 June 2007; pp. 127-135.

42. Wu, S.P.; Pang, L.; Liu, G.; Zhu, J.Q. Laboratory Study on Ultraviolet Radiation Aging of Bitumen. J. Mater. Civ. Eng. 2010, 22, 767-772. [CrossRef]

43. Tian, Y.; Li, H.; Sun, L.; Zhang, H.; Harvey, J.; Yang, J.; Yang, B.; Zuo, X. Laboratory investigation on rheological, chemical and morphological evolution of high content polymer modified bitumen under long-term thermal oxidative aging. Constr. Build. Mater. 2021, 303, 124565. [CrossRef]

44. Chen, H.; Zhou, Y.; Wang, B. Dynamic mechanical properties of SBS modified asphalt after aging. J. Chang. Univ. (Nat. Sci. Ed.) 2009, 29, 1-5.

45. Jadidi, K.; Khalili, M.; Karakouzian, M. Feasibility of Using Non-Destructive Ultrasound Measurement Technique to Evaluate Binder Content of Asphalt Mixtures. CivilEng 2021, 2, 396-405. [CrossRef]

46. Cong, P.L.; Wang, J.; Li, K.; Chen, S.F. Physical and rheological properties of asphalt binders containing various antiaging agents. Fuel 2012, 97, 678-684. [CrossRef]

47. Tabatabaee, H.A.; Velasquez, R.; Bahia, H.U. Predicting low temperature physical hardening in asphalt binders. Constr. Build. Mater. 2012, 34, 162-169. [CrossRef]

48. Zhang, Z.; Sun, J.; Jia, M.; Ban, X.; Wang, L.; Chen, L.; Huang, T.; Liu, H. Effects of Polyurethane Thermoplastic Elastomer on Properties of Asphalt Binder and Asphalt Mixture. J. Mater. Civ. Eng. 2021, 33, 04020477. [CrossRef]

49. Zhang, Z.; Sun, J.; Jia, M.; Qi, B.; Zhang, H.; Lv, W.; Mao, Z.; Chang, P.; Peng, J.; Liu, Y. Study on a thermosetting polyurethane modified asphalt suitable for bridge deck pavements: Formula and properties. Constr. Build. Mater. 2020, 241, 118122. [CrossRef]

50. Al-Qadi, I.L.; Sheh-Hsein, Y.; Dessouky, S. Development of crack sealant bending beam rheometer (CSBBR) testing to characterize hot-poured bituminous crack sealants at low temperatures. J. Assoc. Asph. Paving Technol. 2007, 76, 85-121.

51. Yang, K.; He, Z.; Li, D.; Xu, H.; Kong, L. Experimental Study on Basalt Fiber Crack Resistance of Asphalt Concrete Based on Acoustic Emission. Materials 2021, 14, 4096. [CrossRef] [PubMed]

52. Specifications for Asphalt Pavement Design of Civil Airport; MH/T 5010-2017. 2017. Available online: https://max.book118.com/ $\mathrm{html} / 2018 / 1104 / 8061064121001131 . s h t m$ (accessed on 28 November 2017). 